\title{
Development and validation of a scoring system for predicting cancer patients at risk of extended-spectrum b-lactamase- producing Enterobacteriaceae infections
}

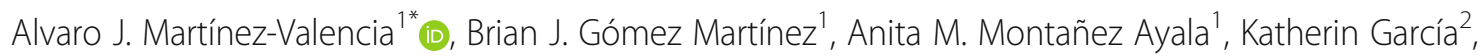
Ricardo Sánchez Pedraza', Leydy P. Jiménez Cetina ${ }^{3}$, Julio C. Gómez Rincón² and Sonia I. Cuervo Maldonado 1,2,4*

\begin{abstract}
Background: Extended-spectrum beta-lactamase producing Enterobacteriaceae (ESBL-PE) infections are frequent and highly impact cancer patients. We developed and validated a scoring system to identify cancer patients harboring ESBL-PE at the National Institute of Cancer of Colombia.

Methods: We retrospectively analyzed medical records of 1695 cancer patients. Derivation phase included 710 patients admitted between 2013 to 2015, ESBL-PE positive culture $(n=265)$ paired by month and hospitalization ward with Non-ESBL-PE $(n=445)$. A crude and weighted score was developed by conditional logistic regression. The model was evaluated in a Validation cohort $(n=985)$ with the same eligibility criteria between 2016 to 2017.

Results: The score was based on eight variables (reported with Odds Ratio and 95\% confidence interval): Hospitalization $\geq 7$ days (5.39 [2.46-11.80]), Hospitalization during the previous year (4, 87 [2.99-7.93]), immunosuppressive therapy during the previous 3 months (2.97 [1.44-6.08]), Neutropenia (1.90 [1.12-3.24]), Exposure to Betalactams during previous month (1.61 [1.06-2.42]), Invasive devices (1.51 [1.012-2.25]), Neoplasia in remission (2.78 [1.25-1.17]), No chemotherapy during the previous 3 months (1.90 [1.22-2.97]). The model demonstrated an acceptable discriminatory capacity in the Derivation phase, but poor in the Validation phase (Recipient Operating Characteristic Curve: 0.68 and 0.55 respectively).

Conclusions: Cancer patients have a high prevalence of risk factors for ESBL-PE infection. The scoring system did not adequately discriminate patients with ESBL-PE. In a high-risk population, other strategies should be sought to identify patients at risk of resistant ESBL-PE infection.
\end{abstract}

Keywords: Beta-lactamases, Extended-spectrum $\beta$-lactamase producing Enterobacteriaceae, Cancer, Prediction, Risk stratification

\footnotetext{
* Correspondence: ajmartinezv@unal.edu.co; sicuervom@unal.edu.co 'Departamento de Medicina Interna. Bogotá, Universidad Nacional de Colombia, Bogotá, D.C., Colombia

Full list of author information is available at the end of the article
}

(C) The Author(s). 2020 Open Access This article is licensed under a Creative Commons Attribution 4.0 International License, which permits use, sharing, adaptation, distribution and reproduction in any medium or format, as long as you give appropriate credit to the original author(s) and the source, provide a link to the Creative Commons licence, and indicate if changes were made. The images or other third party material in this article are included in the article's Creative Commons licence, unless indicated otherwise in a credit line to the material. If material is not included in the article's Creative Commons licence and your intended use is not permitted by statutory regulation or exceeds the permitted use, you will need to obtain permission directly from the copyright holder. To view a copy of this licence, visit http://creativecommons.org/licenses/by/4.0/ The Creative Commons Public Domain Dedication waiver (http://creativecommons.org/publicdomain/zero/1.0/) applies to the data made available in this article, unless otherwise stated in a credit line to the data. 


\section{Summary}

Cancer patients have a high prevalence of risk factors for ESBL-PE infection. The developed scoring system did not adequately discriminate patients with ESBL-PE. In high-risk population other strategies should be sought to identify patients at risk of ESBL-PE infection.

\section{Introduction}

Infections caused by ESBL-PE (Escherichia coli, Klebsiella spp. and Proteus mirabilis) are a major clinical problem and represent a growing proportion of infections acquired in the community and associated with health care worldwide [1-4].

The delay in the initiation of adequate antibiotic treatment against infections caused by ESBL-PE is associated with increased morbidity, duration of hospitalizations, mortality and treatment-related costs [5].

Carbapenems are considered the antibiotics of choice for the treatment of ESBL-PE infections given their stability against the hydrolytic activity of ESBL. However, excessive use of carbapenems promotes the selection of microorganisms resistant to these antibiotics, leaving few therapeutic options to treat infections by resistant microorganisms [6-8].

Identification of patients at risk of ESBL-PE infections could allow timely and adequate selection of appropriate empirical antibiotic treatment, reducing treatment failure, complications, antibiotic costs and inappropriate use of carbapenems with the risk of selecting resistant microorganisms $[9,10]$.

Cancer patients represent an intrinsically vulnerable population to infections, particularly to ESBL-PE. It is recognized that the depressed immune system and frequent lesions in the gastrointestinal mucosa and skin barriers due to surgical interventions, invasive devices or cytotoxic chemotherapy, facilitate the translocation or invasion of tissues and bloodstream by ESBL-PE [11-14]. In addition, frequent use of antibiotics as prophylaxis or treatment has also been linked to increased ESBL-PE infections in cancer patients [15-17].

Several clinical scoring tools have been developed to identify patients at risk of ESBL-PE infection, with different populations and heterogeneous findings [18], although none of them evaluate specifically patients with solid or hematologic malignancies.

The objective of this study was to develop and validate a reliable and easy-to-use clinical scoring system to identify patients with solid or hematologic malignancies with a high risk of ESBL-PE infections at the National Cancer Institute of Colombia (Instituto Nacional de Cancerología).

\section{Methods}

\section{Study design and study site}

A retrospective, analytical study was conducted in cancer patients with documented microbiological isolation during hospitalization at the National Cancer Institute of Colombia; an institution located in Bogotá with 180 beds and an admission rate of 14,000 patients/year, national reference center for solid and hematological cancer care in the country.

A case-control study (Derivation phase) was carried out to identified risk factors in cancer patients for microbiological isolation of ESBL-PE in any clinical sample, then a scoring system was developed assigning weight to each factor. The scoring system was evaluated in a cohort admitted on a different date (Validation phase).

\section{Inclusion criteria and case definition}

Patients admitted to the hospital of any sex and age, with a confirmed oncological diagnosis (independent of stage or activity of cancer) and microbiological isolation of Enterobacteriaceae in any clinical sample since admission to the hospital were included. Patients with prior isolation of ESBL-PE or incomplete information of the study variables were excluded. Only the first culture (index) was taken into account in case of more than one isolation. The cases consisted of patients admitted between 1 January 2013 and 31 December 2015, with ESBL-PE isolation; two controls were sought for each case with isolation of non-ESBL-PE, paired for the same month and hospitalization ward at the time of index culture. Patients included in the Validation phase were admitted between 1 January 2016 and 31 December 2017, with the same eligibility criteria. Patients were only included in a single phase of the study.

\section{Collection of data and variables}

Patients were selected from the microbiology laboratory database and the inclusion performed chronologically until the sample size was completed. The closest control to the date of the index culture of the corresponding case was selected. Information was obtained from laboratory reports and electronic medical records. The study variables included demographic information (sex, admission site, hospitalization room), cancer-related (hematological or solid malignancy, active or remission malignancy according to the medical record of the treating physician), comorbidities (liver disease, kidney disease, diabetes mellitus, lung disease chronic obstructive, heart failure, cerebrovascular disease, dementia, connective tissue disease, acquired immunodeficiency syndrome), Charlson comorbidity index [19], healthcarerelated (hospitalization during the last year, length of hospital stay ( $\geq 7$ days), immunosuppression [prednisone $7.5 \mathrm{mg}$ per day, tacrolimus, sirolimus, cyclosporine, mycophenolate, during the previous 2 weeks] radiation therapy in the previous 3 months, chemotherapy in the previous 3 months, neutropenia at the time of culture, 
use of invasive devices [central venous catheter, bladder catheter, surgical drains or nasogastric tube], surgeries during the last year, antimicrobial use in the last month) and microbiological (isolated microorganism, antimicrobial susceptibility). To reduce errors in data capture, the information was recorded electronically in REDCap ${ }^{\circ}$ and was independently verified by an institutional monitor to identify discrepancies.

\section{Microbiological analysis}

Cultures were ordered according to criteria of the attending physician and carried out following institutional protocols. The Vitek 2 system (bioMerieux, Inc., Hazelwood, MO) or Phoenix (Becton Dickinson Microbiology Systems) fluorimetry and colorimetry for species identification and colorimetry and turbidimetry for susceptibility assessment was used. Phenotypic detection was performed according to recommendations and cut-off points for cefotaxime and ceftazidime and the combination of both with clavulanic acid according to the Vitek 2 and Phoenix 100 panel following the recommendations and current cut-off points of CLSI for Colombia without confirmation by molecular biology [20].

\section{Sample size}

For the derivation phase, a number of 10 events per variable included in the model was taken into account [21]. A total of 28 study variables were evaluated, 280 cases (ESBL-PE event) and 560 controls were estimated to be included, with a ratio of cases to controls of 1:2. For the validation phase, 985 patients were included, taking into account an estimated sensitivity and specificity of the scoring system of $80 \%$, an approximate prevalence of ESBL-PE infections of 25\% [3, 22] and an accuracy of 5\% around the estimator.

\section{Statistical analysis}

For categorical variables absolute and relative frequencies were calculated, the Chi2 test or Fisher's exact test was applied to estimate differences between groups. For continuous variables, normality assumptions were validated from the Shapiro-Wilk test. In variables with normal distribution, averages and standard deviations were calculated, otherwise, medians and ranges were estimated. To establish comparisons between groups, the TStudent or U-Mann-Whitney test was applied. In the bivariate analysis, those variables with a significance value of less than 0.15 were incorporated into the multivariable conditional logistic regression analysis. Variables incorporated in the final model were selected using a "stepwise" strategy, maintaining probability input values of 0.15 . The final model was transformed into a raw score: assigning an equal score for each variable, and also a weighted score: each variable with a score calculated by dividing each regression coefficient by half of the smallest coefficient and rounded to the nearest integer [23]. The discriminatory power of the model was determined by calculating sensitivity, specificity and Area Under the Receiver Operating Characteristic Curve (AUC-ROC). The optimal cutting points were established by the method proposed by Liu [24]. Additionally, sensitivity, specificity, positive and negative predictive values (PPV and NPV, respectively) were estimated with different cut-off points. Except for the "stepwise" procedures, $5 \%$ significance values were used and two-tailed hypotheses were tested. All statistical analyses were performed with Stata $13^{\circ}$.

\section{Ethical considerations}

The study was approved by the Institutional Review Boards of the Universidad Nacional de Colombia and Instituto Nacional de Cancerología. Written informed consent was not required.

\section{Results \\ Derivation phase}

A total of 265 cases with a positive culture for ESBL-PE met the eligibility criteria. For 180 cases their respective 2 paired controls were found, for the remaining 85 cases, only 1 paired control met all the eligibility criteria. In total, 710 patients were included in the derivation phase. The median age for cases was 56 years, $56 \%$ were men, 231 (87\%) were admitted through the emergency department, the majority had a solid tumor $(70 \%)$ and active malignancy (92\%). E. coli and Klebsiella spp. represented $98 \%$ of the microbiological isolates of the cases (Table 1).

The multivariable conditional logistic regression analysis showed eight variables independently associated with the microbiological isolation of ESBL-PE: Hospitalization during the last year $(p=0.000)$, Prolonged hospitalization $\geq 7$ days $(\mathrm{p}=0.000)$, Immunosuppressive therapy during the 3 months previous $(p=0.003)$, Neutropenia $(p=0.017)$, Exposure to Betalactam drugs in the previous month $(p=0.022)$, Use of invasive devices $(p=0.038)$, Neoplasm in remission $(p=0.012)$ and No use of chemotherapy in the last 3 months $(p=0.004)$. A crude and weighted scoring system was constructed with the identified variables (Table 2).

The crude score achieved an acceptable ability to discriminate patients with ESBL-PE isolation from patients without ESBL-PE (AUC-ROC: 0.684 95\% CI 0.6460.722 ). The weighted score achieved a similar capacity (AUC-ROC: 0.687 95\% CI 0.648-0.726). For simplicity, it was decided to apply the crude score in the validation cohort. 
Table 1 Characteristics of cancer patients with Enterobacteriaceae isolation. Derivation Phase

\begin{tabular}{|c|c|c|c|}
\hline Total, No. (\%) & $\begin{array}{l}\text { Cases } \\
\text { (ESBL-PE) } n=265 \text { (37) }\end{array}$ & $\begin{array}{l}\text { Controls } \\
\text { (non-ESBL-PE) } n=445 \text { (63) }\end{array}$ & $p$ \\
\hline \multicolumn{4}{|l|}{ Clinical characteristics } \\
\hline Age, median (IQR), years & $56(39-67)$ & $60(47-70)$ & 0.009 \\
\hline Age $\geq 70$ years & $49(18)$ & $114(25)$ & 0,029 \\
\hline Men & $148(56)$ & $286(64)$ & 0.026 \\
\hline Admission as an outpatient & $231(87)$ & $425(96)$ & 0.000 \\
\hline Solid tumor & $186(70)$ & $336(76)$ & 0.120 \\
\hline Hematological malignancy & $79(30)$ & $109(34)$ & \\
\hline Active neoplasia & $245(92)$ & $428(96)$ & 0.031 \\
\hline Neoplasia in remission & $20(8)$ & $17(4)$ & \\
\hline \multicolumn{4}{|l|}{ Comorbidities } \\
\hline Acute myocardial infarction & $6(1,5)$ & $7(2,2)$ & 0,050 \\
\hline Symptomatic heart failure & $5(1,8)$ & $9(2)$ & 0,900 \\
\hline Peripheral arterial disease & $1(0,38)$ & $1(0,22)$ & 0,711 \\
\hline Cerebrovascular disease & $2(0,7))$ & $3(0,6))$ & 0,901 \\
\hline Dementia & $2(0,7)$ & $4(0,9)$ & 0,839 \\
\hline Chronic obstructive pulmonary disease & $14(5,2)$ & $18(4,0)$ & 0,442 \\
\hline Connective tissue disease & $2(0,7)$ & $8(1,8)$ & 0,254 \\
\hline Peptic acid disease & $2(0,7)$ & $3(0,6)$ & 0,901 \\
\hline Chronic liver disease & $5(1,8)$ & $6(1,3)$ & 0,574 \\
\hline Mellitus diabetes & $18(6,7)$ & $44(9,8)$ & 0,158 \\
\hline Hemiplegia & $9(3,4)$ & $12(2,7)$ & 0,595 \\
\hline Renal disease & $20(7,5)$ & $28(6,2)$ & 0,519 \\
\hline Metastasis & $85(32)$ & $135(30)$ & 0,628 \\
\hline AIDS & $4(1,5)$ & $3(0,6)$ & 0,276 \\
\hline Charlson comorbidity index $\geq 4$ & $104(39)$ & $167(36)$ & 0,649 \\
\hline \multicolumn{4}{|l|}{ Medical interventions } \\
\hline Hospitalization during previous year & $223(84)$ & $264(59)$ & 0.000 \\
\hline Prolonged hospitalization ( $\geq 7$ days) & $119(45)$ & $141(32)$ & 0.000 \\
\hline Immunosuppressive therapy ${ }^{a}$ & $27(10)$ & $19(4)$ & 0,002 \\
\hline Radiation therapy ${ }^{a}$ & $23(9)$ & $43(10)$ & 0.662 \\
\hline Chemotherapy $^{a}$ & $89(34)$ & $183(41)$ & 0.046 \\
\hline Neutropenia at the time of culture & $59(22)$ & $68(15)$ & 0.019 \\
\hline Surgical procedures during previous year & $130(49)$ & $168(38)$ & 0.003 \\
\hline Invasive devices at the time of culture ${ }^{b}$ & $146(55)$ & $177(40)$ & 0.000 \\
\hline Urinary catheter during last month & $93(35)$ & $127(29)$ & 0,068 \\
\hline \multicolumn{4}{|c|}{ Antibiotic use during previous month to index culture } \\
\hline Any antibiotic & $102(38)$ & $108(24)$ & 0,000 \\
\hline Beta-lactams & $80(31)$ & $82(18)$ & 0,000 \\
\hline Aminoglycosides & $5(2)$ & $2(0,4)$ & 0,108 \\
\hline Quinolones & $10(3,8)$ & $8(1,8)$ & 0,136 \\
\hline Carbapenemic & $26(10)$ & $16(3,6)$ & 0,001 \\
\hline Cotrimoxazole & $11(4)$ & $7(1,5)$ & 0,045 \\
\hline Others & $21(8)$ & $23(5)$ & 0,125 \\
\hline
\end{tabular}


Table 1 Characteristics of cancer patients with Enterobacteriaceae isolation. Derivation Phase (Continued)

\begin{tabular}{lll}
\hline Total, No. (\%) & $\begin{array}{l}\text { Cases } \\
\text { (ESBL-PE) } \boldsymbol{n = 2 6 5 ( 3 7 )}\end{array}$ & $\begin{array}{l}\text { Controls } \\
\text { (non-ESBL-PE) } \boldsymbol{n = 4 4 5}(\mathbf{6 3})\end{array}$ \\
\hline $\begin{array}{ll}\text { Isolate source } \\
\text { Blood }\end{array}$ & $63(23)$ & $86(19)$ \\
Urinary tract & $142(54)$ & $272(61)$ \\
Surgical wound & $47(18)$ & $68(15)$ \\
Skin and soft tissues & $3(1)$ & $4(1)$ \\
Lower respiratory tract & $10(4)$ & $15(3)$ \\
Isolated microorganism & & \\
$\quad$ E. coli. & $166(63)$ & $299(67)$ \\
Klebsiella spp. & $92(35)$ & $80(18)$ \\
Proteus spp. & $3(1)$ & $55(12)$ \\
Others & $4(2)$ & $11(2)$ \\
\hline
\end{tabular}

${ }^{a}$ during the previous 3 months, ${ }^{b}$ central venous catheter, dialysis catheter, surgical drains, bladder catheter, nephrostomy, nasogastric tube

\section{Validation phase}

Consecutively, from 1 January 2016 to 26 December 2017, all patients were included until the sample size of 985 cancer patients with a positive culture for Enterobacteriaceae was completed. More than half of patients were older than 58 years, men represented 39\%, the majority (51\%) were admitted through the emergency department. E. coli and Klebsiella spp. accounted for $83 \%$ of microbiological isolates. The prevalence of ESBL-PE isolates was $19 \%$. In the Validation cohort, there was a larger proportion of women $(p=004)$, lower frequency of hospitalization during the last year $(p=0.000)$, lower frequency of use of immunosuppressive therapy $(p=0.001)$ and lower frequency of isolation of Klebsiella spp. $(p=0.000)$ (Table 3).

\section{Scoring system application}

In the Derivation phase, cases had an average and standard deviation (SD) of $4.05+/-1.11$ points and controls $3.23+/-1.23$ points $(p=0.000)$ (Fig. 1$)$. The crude score with the best operating performance was $\geq 4$ points, with a sensitivity of $68 \%$, specificity of $61 \%$ and an accuracy of $63 \%$.
In the Validation phase, patients with ESBL-PE had an average of $2.9+/-1.3$ points and patients with nonESBL-PE $2.4+/-1.2$ points $(\mathrm{p}=0.000)$ (Fig. 2$)$. Using the cut-off point $\geq 4$ points, a sensitivity of $32 \%$, a specificity of $83 \%$ and accuracy of $73 \%$ was obtained (Table 4 ). The crude score achieved an acceptable ability to discriminate patients with ESBL-PE isolation (AUC-ROC: 0.6042 95\% CI 0.560-0.647) (Fig. 3).

Subgroup analysis of blood cultures $(n=184)$ within the Validation phase showed an average of $3.36+/-1.27$ points for ESBL-PE and $2.59+/-1.21$ for non- ESBL-PE ( $p=0.002)$. With the cut-off point $\geq 4$ points, a sensitivity of $43 \%$, specificity of $83 \%$ and accuracy of $77 \%$ were obtained. The crude score achieved an acceptable ability to discriminate patients with ESBL-PE isolation (AUCROC: 0.6722 95\% CI 0.569-0.774) (Supplement).

\section{Discussion}

ESBL-PE infections have increased in recent years and are a major cause of hospital and community-acquired infections $[1,3,4,12,25,26]$. The carrier status in the healthy population is estimated at $14 \%$ worldwide, but in some regions, it can be as high as $46 \%$ [2]. Colonization

Table 2 Risk factors for ESBL-PE isolation. Derivation Phase

\begin{tabular}{|c|c|c|c|c|c|}
\hline Variable & Adjusted Odds ratio (IC 95\%) & $p$ & Regression coefficient & Weighted score & Crude score \\
\hline Prolonged hospitalization ( $\geq 7$ days) & $5,39(2,46-11,80)$ & 0.000 & 1,68 & 8 & 1 \\
\hline Hospitalization during previous year & $4,87(2,99-7,93)$ & 0.000 & 1,58 & 7 & 1 \\
\hline Immunosuppressive therapy ${ }^{a}$ & $2,97(1,44-6,08)$ & 0,003 & 1,08 & 5 & 1 \\
\hline Neutropenia & $1,90(1,12-3,24)$ & 0,017 & 0,64 & 3 & 1 \\
\hline Beta-lactams during the previous month & $1,61(1,06-2,42)$ & 0,022 & 0,47 & 2 & 1 \\
\hline Invasive devices at the time of culture ${ }^{b}$ & $1,51(1,01-2,25)$ & 0,038 & 0,41 & 2 & 1 \\
\hline Neoplasia in remission & $2,78(1,25-6,17)$ & 0,012 & 1,02 & 5 & 1 \\
\hline No chemotherapy ${ }^{a}$ & $1,90(1,22-2,97)$ & 0,004 & 0,64 & 3 & 1 \\
\hline
\end{tabular}

${ }^{a}$ during the previous 3 months, ${ }^{b}$ central venous catheter, dialysis catheter, surgical drains, bladder catheter, nephrostomy, nasogastric tube 
Table 3 Comparison of patient in Derivation and Validation phase

\begin{tabular}{|c|c|c|c|c|c|c|}
\hline \multirow[t]{2}{*}{ Total, No. (\%) } & \multicolumn{3}{|l|}{ Derivation } & \multicolumn{3}{|l|}{ Validation } \\
\hline & $\begin{array}{l}\text { Cases } \\
\text { (ESBL-PE) } \\
n=265 \text { (37) }\end{array}$ & $\begin{array}{l}\text { Controls } \\
\text { (non-ESBL-PE) } \\
n=445(63)\end{array}$ & $p$ & $\begin{array}{l}\text { ESBL-PE } \\
n=188 \text { (19) }\end{array}$ & $\begin{array}{l}\text { non-ESBL-PE } \\
n=797(81)\end{array}$ & $p$ \\
\hline Age, median (IQR), years & $56(39-67)$ & $60(47-70)$ & 0.009 & $55(38-67)$ & $59(45-70)$ & 0.009 \\
\hline Men & $148(56)$ & $286(64)$ & 0.026 & $80(43)$ & 309 (39) & 0.340 \\
\hline Emergency room at index culture & $231(87)$ & $425(96)$ & 0.000 & $93(59)$ & $405(51)$ & 0.850 \\
\hline Prolonged hospitalization ( $\geq 7$ days) & $119(45)$ & $141(32)$ & 0.000 & $72(38)$ & $244(30)$ & 0.042 \\
\hline Hospitalization during previous year & $223(84)$ & $264(59)$ & 0,000 & $129(69)$ & $542(68)$ & 0.871 \\
\hline Immunosuppressive therapy ${ }^{a}$ & $27(10)$ & $19(4)$ & 0.002 & $4(2)$ & $10(1)$ & 0.363 \\
\hline Chemotherapy $^{a}$ & $89(34)$ & $183(41)$ & 0.046 & $79(42)$ & $330(41)$ & 0.877 \\
\hline Invasive device at the time of culture ${ }^{b}$ & $146(55)$ & $177(40)$ & 0.000 & $98(52)$ & $348(43)$ & 0.036 \\
\hline Neoplasia in remission & $20(8)$ & $17(4)$ & 0.031 & $11(6)$ & $30(4)$ & 0.197 \\
\hline Neutropenia & $59(22)$ & $68(15)$ & 0.019 & $28(15)$ & $97(12)$ & 0.313 \\
\hline Beta-lactam use & $80(31)$ & $82(18)$ & 0,000 & $49(26)$ & $99(12)$ & 0.000 \\
\hline \multicolumn{7}{|l|}{ Isolate source } \\
\hline Blood & $63(23)$ & $86(19)$ & 0.384 & $30(16)$ & $154(19)$ & 0.651 \\
\hline Urinary tract & $142(54)$ & $272(61)$ & & $123(65)$ & $485(61)$ & \\
\hline Surgical wound & $47(18)$ & $68(15)$ & & $11(6)$ & $62(8)$ & \\
\hline Skin and soft tissues & $3(1)$ & $4(1)$ & & $17(9)$ & $62(8)$ & \\
\hline Lower respiratory tract & $10(4)$ & $15(3)$ & & $7(4)$ & $34(4)$ & \\
\hline \multicolumn{7}{|l|}{ Isolated microorganism } \\
\hline E. coli. & $166(63)$ & $299(67)$ & 0.000 & $134(71)$ & $505(63)$ & 0.002 \\
\hline Klebsiella spp. & $92(35)$ & $80(18)$ & & $33(18)$ & $148(19)$ & \\
\hline Proteus spp. & $3(1)$ & $55(12)$ & & $5(3)$ & $94(12)$ & \\
\hline Others & $4(2)$ & $11(2)$ & & $16(9)$ & $50(6)$ & \\
\hline
\end{tabular}

a during the previous 3 months, ${ }^{\text {b }}$ central venous catheter, dialysis catheter, surgical drains, bladder catheter, nephrostomy, nasogastric tube

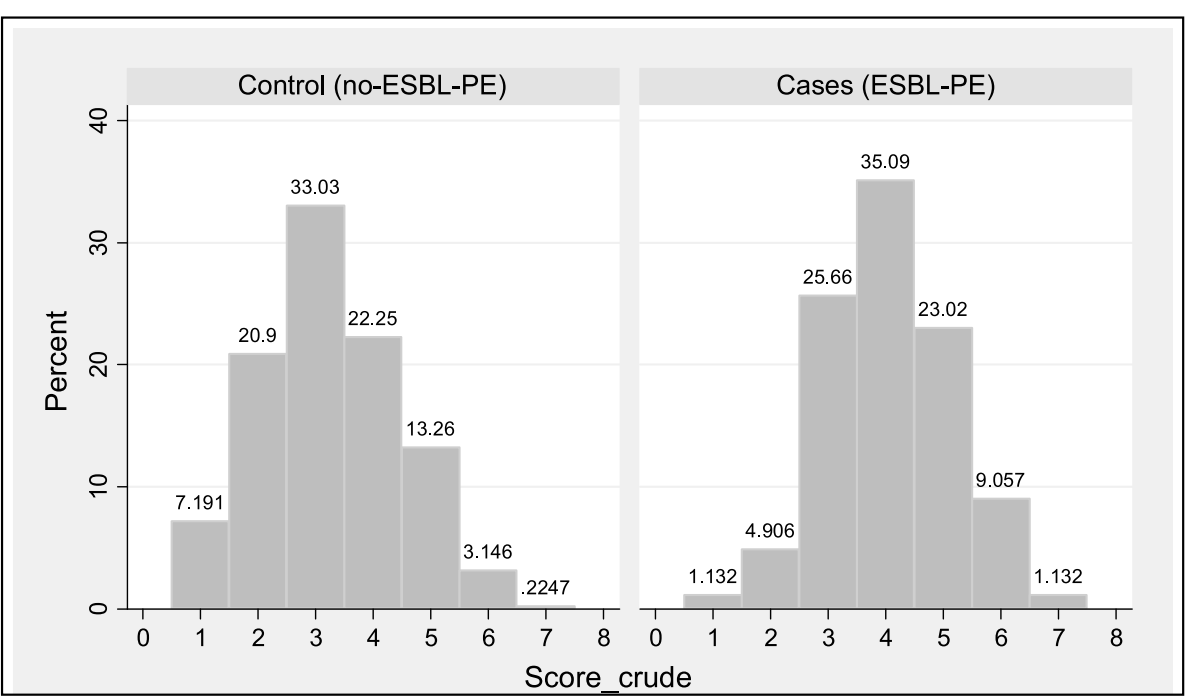

Fig. 1 Distribution of crude score. Derivation Phase 


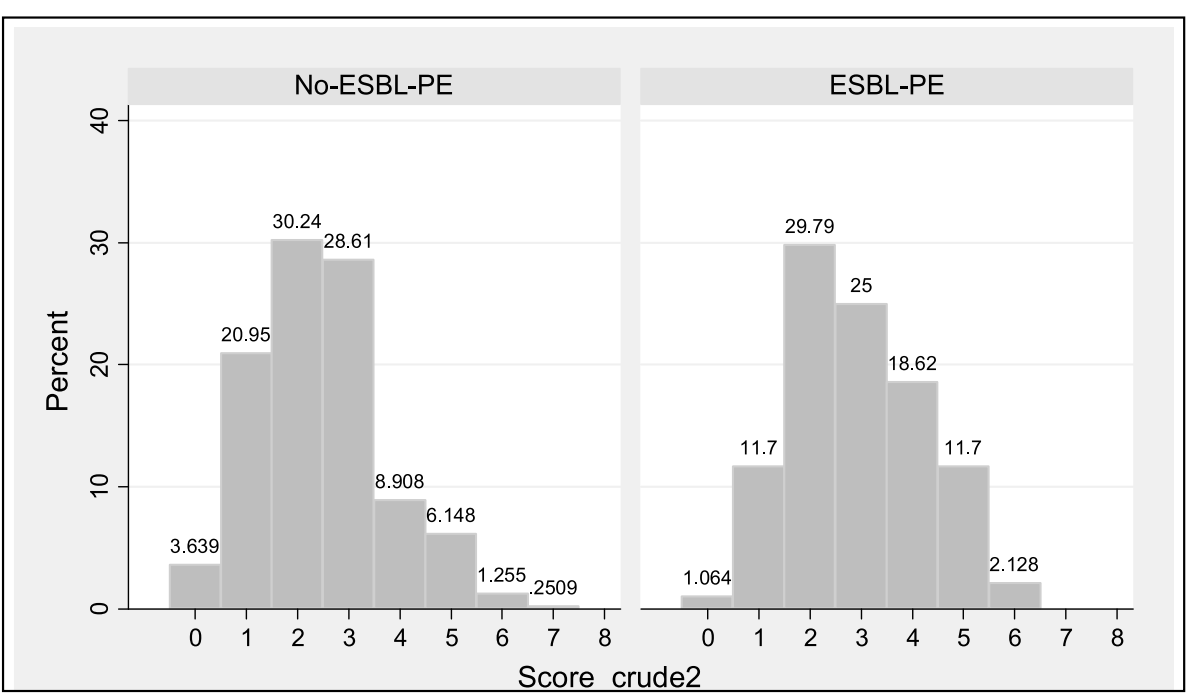

Fig. 2 Distribution of crude score. Validation Phase

status increases in populations at higher risk such as patients with solid or hematological malignancies, with a prevalence of $19 \%$ [25]. In Colombia, communityacquired urinary tract infections produced by Enterobacteriaceae with resistance to third-generation cephalosporins range from 3.4 to $17.2 \%$ [4].

Colonization by ESBL-PE is an important risk factor for subsequent infection or bacteremia by these microorganisms [12, 17, 27]. Other clinical characteristics of the patients, the epidemiological environment and the healthcare-related procedures are recognized as risk factors for ESBL-PE infection [9].

This study evaluated risk factors for isolation of ESBL$\mathrm{PE}$ in cancer patients, derived and validated a scoring system to quickly identify these patients. The multivariable analysis identified eight variables associated with microbiological isolation of ESBL-PE, these included

Table 4 Classification of patients according to the crude score in the Derivation and Validation phase

\begin{tabular}{llllllll}
\hline $\begin{array}{l}\text { Crude } \\
\text { score }\end{array}$ & \multicolumn{2}{l}{$\begin{array}{l}\text { Derivation } \\
\text { Number of patients (\%) }\end{array}$} & \multicolumn{3}{l}{$\begin{array}{l}\text { Validation } \\
\text { Number of patients (\%) }\end{array}$} \\
\cline { 2 - 3 } & Cases & Controls & Total & & ESBL-PE & Non ESBL-PE & Total \\
\hline 0 & $0(0)$ & $0(0)$ & 0 & $2(1)$ & $29(3)$ & 31 \\
1 & $3(1)$ & $32(7)$ & 35 & & $22(11)$ & $167(20)$ & 189 \\
2 & $13(5)$ & $93(20)$ & 106 & $56(29)$ & $241(30)$ & 297 \\
3 & $68(25)$ & $147(33)$ & 215 & $47(25)$ & $228(28)$ & 275 \\
4 & $93(35)$ & $99(22)$ & 192 & $35(18)$ & $71(9)$ & 106 \\
5 & $61(23)$ & $59(13)$ & 120 & $22(11)$ & $49(6)$ & 71 \\
6 & $24(9)$ & $14(3)$ & 38 & $4(2)$ & $10(1)$ & 14 \\
7 & $3(1)$ & $1(0)$ & 4 & $0(0)$ & $2(0)$ & 2 \\
Total & 265 & 445 & 710 & 188 & 797 & 985 \\
\hline
\end{tabular}

hospitalization in the last year, prolonged hospitalization greater than 7 days, immunosuppressive therapy by glucocorticoids or calcineurin inhibitors, presence of neutropenia, use of invasive devices, exposure to betalactam drugs in the previous month, remission neoplasia and no use of chemotherapy in the last 3 months. These factors confirm some already identified in previous studies [9]. The developed score includes simple variables to be evaluated clinically upon the first contact with the patient.

The crude scoring system achieved an acceptable ability to discriminate patients with ESBL-PE. Operational performance was better for the Derivation Phase; however, it fell in the Validation Phase (ROC-AUC 0.68 and 0.60 ). The cut-off point $\geq 4$ points selected by the Liu method [24] that maximizes sensitivity and specificity showed generally low values in both phases (sensitivity 68 and 32\%, specificity 61 and 83\% respectively), also, the accuracy was low, with misclassification of $30 \%$.

The scoring systems can not only be measured with the capacity of maximum discrimination with the ROCAUC because the objective of their implementation must also be taken into account. If the goal is to screen hospitalized patients to determine their risk of ESBL-PE infection, a cut-off point with maximum sensitivity should be sought to capture the majority of patients at risk, with the price of lowering specificity; in this scenario, patients would receive treatment with carbapenems and contact isolation. The limitation of this approach is that many patients without ESBL-PE infection would end up receiving broad-spectrum antibiotics and contact isolation without needing. On the other hand, if the objective is to guide antibiotic therapy, specifically to avoid the indiscriminate use of carbapenems, a cut-off point with 


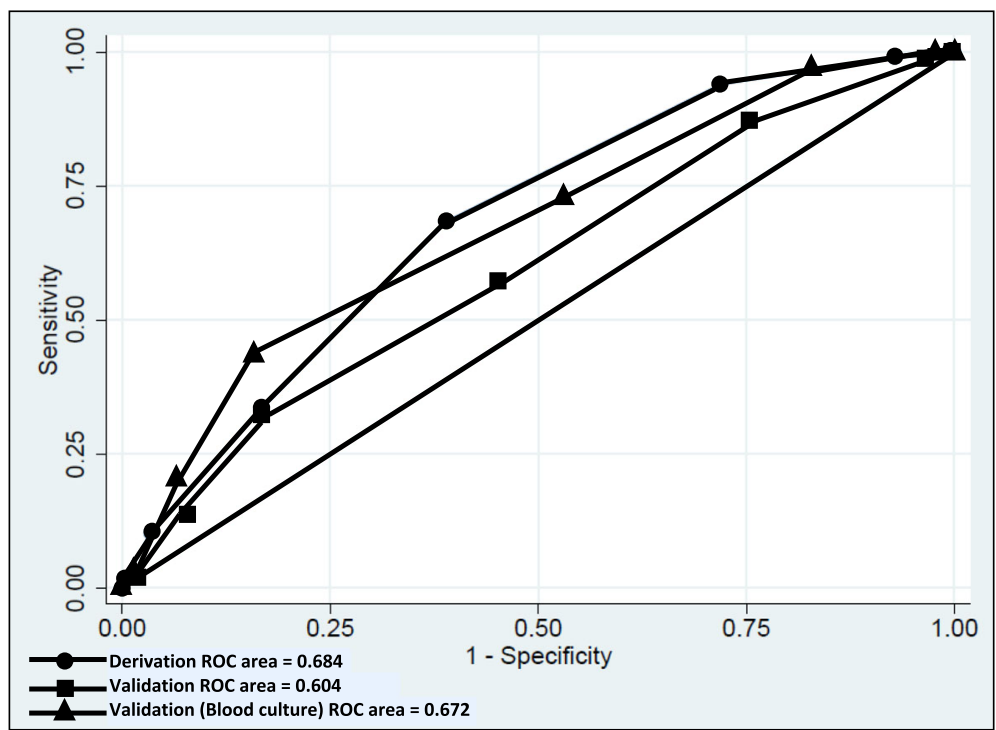

Fig. 3 Receiver Operational Characteristic Curve Analysis with crude score. Derivation and validation phase

low sensitivity and high specificity should be sought $[28,29]$.

In Tumbarello study [23], the cut-off point of at least 3 points had high sensitivity (93\%) and NPV (97\%), but low specificity (62\%) and PPV (45\%); when the cut-off point rose to 6 , sensitivity and NPV decreased to 63 and $88 \%$, but specificity and PPV increased to 95 and $80 \%$. In the Duke model [30], with a cut-off point of 8 points, good specificity and PPV (95 and 79\%, respectively) were obtained, but low sensitivity (58\%). In the Kengkla study [31] the 9-point cut-off obtained moderate sensitivity (74\%) and NPV (68\%) with inadequate specificity (66\%). The most recent model proposed by Lee [32] obtained high sensitivity (84\%) and specificity (92\%) using a cutoff greater than 2 points. These studies included different populations and variables.

In the present study, setting the highest sensitivity (cut-off point $\geq 1$ ) in the Derivation and Validation phases, showed that majority of patients had at least 1 risk factor (sensitivity of 100 and $99 \%$ respectively), but with a high percentage of false positives (100 and 97\%). This makes the scale impractical to exclude patients without risk of ESBL-PE infection and would overestimate the empirical use of carbapenems and the need for contact isolation. Maximizing specificity (cut-off point 27) allows to identify patients without ESBL-PE (100\% specificity), but only $1 \%$ of patients with ESBL-PE are captured, with low capacity to select patients at high risk of ESBL-PE. This way, a large number of patients who may require carbapenem treatment would not receive it and therefore the risk of mortality could increase. It is considered that with this scoring system there is no good cut-off point to predict a high risk of ESBL-PE infection nor to make decisions about the prescription of empirical antibiotics.

Previous described scoring systems may have better discriminatory performance because of the inclusion of more selected populations like the inclusion of patients within the first $48 \mathrm{~h}$ of admission, only with $E$. coli infection or presence of bacteremia [18]. This study included patients of all age ranges, patients with infection or colonization, all Enterobacteriaceae species, community and hospital-acquired infections, as well as infection of any organ. These characteristics reflect better the behavior of infections in the real life of an institution to make the results more generalizable. The subgroup analysis of blood cultures reflected similar performance to the whole validation cohort (Supplement).

The Validation cohort showed that the population attending the National Institute of Cancer of Colombia had a higher prevalence of ESBL-PE than the ambulatory population in Colombia, especially E.coli (19\% vs. 6.4\%) $[4,22]$. Also, this population is highly morbid, approximately $70 \%$ required hospitalization in the last year, $40 \%$ received chemotherapy in the last 3 months, $45 \%$ had an invasive device and $25 \%$ was exposed to antibiotics in the last month.

In the context of patients with cancer and immunosuppression, the current therapeutic behavior is oriented to establishing the patient's risk group and beginning empirical treatment with broad-spectrum antibiotics until microbiological isolation is achieved. This approach has been proposed recently, based on observational studies where patients are classified according to the immune status, source of infection and severity of disease presentation $[7,8]$. For immunosuppressed patients (e.g. 
neutropenia, leukemia, lymphoma, HIV, solid organ or hematopoietic cell transplantation, cytotoxic chemotherapy or steroid use) and severely ill patients (high Pitt or APACHE II score, need for ICU or presence of septic shock) the beginning of empirical treatment with carbapenems has been recommended [8].

The results of this study allow us to conclude that in patients at high risk for ESBL-PE infections such as cancer patients, the risk score fails to adequately discriminate the patients and therefore other methods should be evaluated to early identify patients with ESBL-PE infections and to guide antibiotic therapy [33, 34].

The limitations of the study include its retrospective nature, historic medical records as source of information; the lack of inclusion of some specific variables of cancer patients (type of neoplasia, type of chemotherapy, ECOG and Karnofsky scores) which could have provided more information or allowed a better classification of patients; the absence of distinction between infection vs colonization, variables that are retrospectively difficult to discriminate and are proposed to be validated prospectively and non-discrimination between infection from the community or healthcare-associated. Finally, it is single specialized cancer institution in Colombia and therefore the results are not generalizable to other institutions with different characteristics. The findings of the neoplasia in remission and absence of chemotherapy in the previous 3 months as risk factors for ESBL-PE are inconsistent with previous studies and warrant confirmation in the context of cancer patients.

\section{Conclusions}

Cancer patients have a high prevalence of risk factors for ESBL-PE infection. The scoring system did not adequately discriminate patients with ESBL-PE. In a highrisk population, other strategies should be sought to identify patients at risk of resistant ESBL-PE infection.

\section{Supplementary information}

Supplementary information accompanies this paper at https://doi.org/10. 1186/s12879-020-05280-4.

Additional file 1.

\section{Abbreviations}

ESBL-PE: Extended-spectrum beta-lactamase producing Enterobacteriaceae; OR: Odds Ratio; AUC-ROC: Area Under the Receiver Operating Characteristic Curve; PPV: Positive predictive values; NPV: Negative positive predictive values; SD: Standard deviation

\section{Acknowledgements}

We are thankful to all the members of the research group GREICAH (Grupo de Investigación en Enfermedades Infecciosas en Cáncer y Alteraciones Hematológicas): Leonardo Gómez García, Sergio Alejandro Gómez, Lina María Quitian, Nicolás Castellanos, Juan Diego Buriticá and Paola Nova. We would also like to thank the research team at the Instituto Nacional de Cancerología and the microbiology laboratory.

\section{Authors' contributions}

AMV, BG, LJ, RS, JG and SC participated in the conception and design of the study. AMV, BG, AMA, KG, LJ collected the data. AMV, BG, AMA, RS performed the statistical analysis. AMV drafted the manuscript. AMV, BG, AMM, RS, JG and SC revised the paper critically for substantial intellectual content. All authors read and approved the final manuscript.

\section{Authors' information}

AMV and BG are residents of Internal Medicine. AMA is an epidemiologist research associate in the Internal Medicine Department. KG is an M.D. research associated with the Instituto Nacional de Cancerología. RS is an expert epidemiologist associated with Instituto Nacional de Cancerología and the Universidad Nacional de Colombia. $L J$ is a microbiologist research associated with Instituto Nacional de Cancerología. JG is an Infectious Diseases specialist associated with associated with Instituto Nacional de Cancerología. SC is an Infectious Diseases professor and research group leader associated with Internal Medicine Department at Universidad Nacional de Colombia and the Instituto Nacional de Cancerología.

\section{Funding}

This work was supported by the National Call for Projects to Strengthen Research, Creation and Innovation of the National University of Colombia 2016-2018 [HERMES code: 35435], [QUIPU code: 202010026772]. The funder had no role in the design of the study and collection, analysis, and interpretation of data and in writing the manuscript.

\section{Availability of data and materials}

The datasets used and/or analyzed during the current study is available from the corresponding author on reasonable request.

\section{Ethics approval and consent to participate}

The study was approved by the Institutional Review Boards of the National University of Colombia and Instituto Nacional de Cancerología. Written informed consent was not required. The procedures followed were in accordance with the ethical standards set by the institutional ethics committee and that of the Declaration of Helsinki.

Consent for publication

Not applicable.

\section{Competing interests}

The authors declare that they have no competing interests.

\section{Author details}

${ }^{1}$ Departamento de Medicina Interna. Bogotá, Universidad Nacional de Colombia, Bogotá, D.C., Colombia. ${ }^{2}$ Grupo de Enfermedades Infecciosas, Instituto Nacional de Cancerología E.S.E, Bogotá, D.C., Colombia. ${ }^{3}$ Laboratorio de Microbiología, Instituto Nacional de Cancerología E.S.E, Bogotá, D.C., Colombia. ${ }^{4}$ Grupo en Enfermedades Infecciosas en Cáncer y Alteraciones Hematológicas (GREICAH), Bogotá, D.C., Colombia.

Received: 4 March 2020 Accepted: 20 July 2020

Published online: 31 July 2020

\section{References}

1. Tacconelli E, Magrini N. WHO | Global priority list of antibiotic-resistant bacteria to guide research, discovery, and development of new antibiotics. Who. World Health Organization; 2017. p. 7.

2. Karanika S, Karantanos T, Arvanitis M, Grigoras C, Mylonakis E. Fecal colonization with extended-spectrum Beta-lactamase-producing Enterobacteriaceae and risk factors among healthy individuals: a systematic review and Metaanalysis. Clin Infect Dis. 2016;63(3):310-8.

3. González L, Cortés JA. Revisión sistemática de la farmacorresistencia en enterobacterias de aislamientos hospitalarios en Colombia. Biomédica. 2014; 34(2):180-97.

4. Leal AL, Cortés JA, Arias G, Ovalle MV, Saavedra SY, Buitrago G, et al. Emergencia de fenotipos resistentes a cefalosporinas de tercera generación en Enterobacteriaceae causantes de infección del tracto urinario de inicio comunitario en hospitales de Colombia. Enferm Infecc Microbiol Clin. 2013; 31(5):298-303. 
5. Schwaber MJ, Navon-Venezia S, Kaye KS, Ben-Ami R, Schwartz D, Carmeli Y. Clinical and economic impact of bacteremia with extended-Spectrumlactamase-producing Enterobacteriaceae. Antimicrob Agents Chemother. 2006:50(4):1257-62.

6. Tamma PD, Rodriguez-Bano J. The Use of Noncarbapenem $\beta$-Lactams for the Treatment of Extended-Spectrum $\beta$-Lactamase Infections. Clin Infect Dis. 2017;64(7):972-80. https://doi.org/10.1093/cid/cix034.

7. Rodriguez-Baño J, Gutiérrez-Gutiérrez B, Machuca I, Pascual A. Treatment of infections caused by extended-Spectrum-Beta. Clin Microbiol Rev. 2018; 31(2):1-42.

8. Gutiérrez-Gutiérrez B, Rodríguez-Baño J. Current options for the treatment of infections due to extended-spectrum beta-lactamase-producing Enterobacteriaceae in different groups of patients. Clin Microbiol Infect. 2019 Apr 12;25(8):932-42.

9. Bassetti M, Carnelutti A, Peghin M. Patient specific risk stratification for antimicrobial resistance and possible treatment strategies in gram-negative bacterial infections. Expert Rev Anti-Infect Ther. 2017;15(1):55-65.

10. Sheu CC, Lin SY, Chang YT, Lee CY, Chen YH, Hsueh PR. Management of infections caused by extended-spectrum $\beta$-lactamase-producing Enterobacteriaceae: current evidence and future prospects. Expert Rev AntiInfect Ther. 2018 Mar 4;16(3):205-18.

11. Biehl LM, Schmidt-Hieber M, Liss B, Cornely OA, Vehreschild MJGT. Colonization and infection with extended spectrum beta-lactamase producing Enterobacteriaceae in high-risk patients - review of the literature from a clinical perspective. Crit Rev Microbiol. 2016;42(1):1-16.

12. Alevizakos M, Gaitanidis A, Andreatos N, Arunachalam K, Flokas E, Mylonakis $E$, et al. Bloodstream infections due to extended-spectrum $\beta$-lactamaseproducing Enterobacteriaceae among patients with malignancy: a systematic review and meta-analysis. Int J Antimicrob Agents. 2017;50(5): 657-63.

13. Van der Velden WJFM, Herbers AHE, Netea MG, Blijlevens NMA. Mucosal barrier injury, fever and infection in neutropenic patients with cancer: introducing the paradigm febrile mucositis. Br J Haematol. 2014;167(4):441-52.

14. Montassier E, Batard E, Gastinne T, Potel G, De La Cochetière MF. Recent changes in bacteremia in patients with cancer: a systematic review of epidemiology and antibiotic resistance. Eur J Clin Microbiol Infect Dis. 2013; 32(7):841-50.

15. Cornejo-Juárez P, Pérez-Jiménez C, Silva-Sánchez J, Velázquez-Acosta C, González-Lara F, Reyna-Flores F, et al. Molecular analysis and risk factors for Escherichia coli producing extended-spectrum $\beta$-lactamase bloodstream infection in hematological malignancies. PLoS One. 2012;7(4):e35780.

16. César-Arce $A$, Volkow-Fernández $P$, Valero-Saldaña LM, Acosta-Maldonado $B$, Vilar-Compte D, Cornejo-Juárez P. Infectious complications and multidrugresistant Bacteria in patients with hematopoietic stem cell transplantation in the first 12 months after transplant. Transplant Proc. 2017:49(6):1444-8.

17. Golzarri MF, Silva-Sánchez J, Cornejo-Juárez P, Barrios-Camacho H, ChoraHernández LD, Velázquez-Acosta $C$, et al. Colonization by fecal extendedspectrum $\beta$-lactamase-producing Enterobacteriaceae and surgical site infections in patients with cancer undergoing gastrointestinal and gynecologic surgery. Am J Infect Control. 2019;000:1-6.

18. Mohd Sazlly Lim S, Wong PL, Sulaiman H, Atiya N, Hisham Shunmugam R, Liew SM. Clinical prediction models for ESBL-Enterobacteriaceae colonization or infection: a systematic review. J Hosp Infect. 2019;102(1):8-16.

19. Charlson M, Szatrowski TP, Peterson J, Gold J. Validation of a combined comorbidity index. J Clin Epidemiol. 1251;47(11):124-1251.

20. Esparza G, Ariza B, Bedoya AM, Bustos I, Castañeda-Ramirez CR, De la

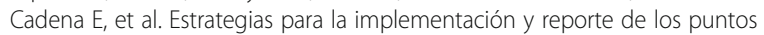
de corte CLSI vigentes y pruebas fenotípicas confirmatorias para BLEE y carbapenemasas en bacilos Gram negativos en laboratorios clínicos de Colombia. Infectio. 2014;17(2):80-9.

21. Pepe, Margaret S. The Statistical Evaluation of Medical Tests for Classification and Prediction. Oxford: Oxford University Press; 2003. Print.

22. Instituto Nacional de Salud (INS). Resultados de la Vigilancia por Laboratorio de Resistencia antimicrobiana en Infecciones Asociadas a la Atención en Salud (IAAS) 2017. 2017.

23. Tumbarello M, Trecarichi EM, Bassetti M, De Rosa FG, Spanu T, Di Meco E, et al. Identifying patients harboring extended-Spectrum- $\beta$-lactamaseproducing Enterobacteriaceae on hospital admission: derivation and validation of a scoring system ${ }^{\nabla}$. Antimicrob Agents Chemother. $2011 \mathrm{Jul}$; 55(7):3485-90
24. Liu X. Classification accuracy and cut point selection. Stat Med. 2012;31(23): 2676-86.

25. Alevizakos M, Karanika S, Detsis M, Mylonakis E. Colonisation with extendedspectrum $\beta$-lactamase-producing Enterobacteriaceae and risk for infection among patients with solid or haematological malignancy: a systematic review and meta-analysis. Int J Antimicrob Agents. 2016 Dec 1;48(6):647-54.

26. Nocua-Báez LC, Cortes-Luna JA, Leal-Castro AL, Arias-León GF, Ovalle-Guerro MV, Saavedra-Rojas SY, et al. Susceptibilidad antimicrobiana de enterobacterias identificadas en infección urinaria adquirida en la comunidad, en gestantes en nueve hospitales de Colombia. Rev Colomb Obstet Ginecol. 2017:68(4):275.

27. Cornejo-Juárez P, Suárez-Cuenca JA, Volkow-Fernández P, Silva-Sánchez J, Barrios-Camacho H, Nájera-León E, et al. Fecal ESBL Escherichia coli carriage as a risk factor for bacteremia in patients with hematological malignancies. Support Care Cancer. 2016:24(1):253-9.

28. Van Griensven J, Florence E, Van Den Ende J. Validation of clinical scores for risk assessment. Clin Infect Dis. 2012;54(10):1520-1.

29. Zweig MH, Campbell G. Receiver-operating characteristic (ROC) plots: a fundamental evaluation tool in clinical medicine. Clin Chem. 1993;39(4):561-77.

30. Johnson SW, Anderson DJ, May DB, Drew RH. Utility of a Clinical Risk Factor Scoring Model in Predicting Infection with Extended-Spectrum $\beta$ Lactamase-Producing Enterobacteriaceae on Hospital Admission. Infect Control Hosp Epidemiol. 2013;34(4):385-92.

31. Kengkla K, Charoensuk N, Chaichana M, Puangjan S, Rattanapornsompong T, Choorassamee J, et al. Clinical risk scoring system for predicting extended-spectrum $\beta$-lactamase-producing Escherichia coli infection in hospitalized patients. J Hosp Infect. 2016.

32. Lee $\mathrm{CH}$, Chu FY, Hsieh CC, et al. A simple scoring algorithm predicting extended-spectrum $\beta$-lactamase producers in adults with community-onset monomicrobial Enterobacteriaceae bacteremia: Matters of frequent emergency department users. Medicine (Baltimore). 2017;96(16):e6648. https://doi.org/10.1097/MD.0000000000006648.

33. Dortet $L$, Poirel $L$, Nordmann P. Rapid detection of extended-spectrum- $\beta$ lactamase-producing Enterobacteriaceae from urine samples by use of the ESBL NDP test. J Clin Microbiol. 2014 Oct 1;52(10):3701-6.

34. Nordmann P, Dortet $L$, Poirel L. Rapid detection of extended-spectrum- $\beta$ lactamase-producing Enterobacteriaceae. J Clin Microbiol. 2012;50(9):301622.

\section{Publisher's Note}

Springer Nature remains neutral with regard to jurisdictional claims in published maps and institutional affiliations.
Ready to submit your research? Choose BMC and benefit from:

- fast, convenient online submission

- thorough peer review by experienced researchers in your field

- rapid publication on acceptance

- support for research data, including large and complex data types

- gold Open Access which fosters wider collaboration and increased citations

- maximum visibility for your research: over $100 \mathrm{M}$ website views per year

At $\mathrm{BMC}$, research is always in progress.

Learn more biomedcentral.com/submission 